\title{
Gestão do conhecimento estratégico estudo dos subfatores sistêmicos aplicados à ECT
}

\author{
Knowledge management strategy a study of the systemic subfactors \\ applied to the Brazilian postal system
}

Ricardo Ken FUJIHARA'

\begin{abstract}
RESUMO
Para avaliar a Gestão do Conhecimento Estratégico (GCE), foi realizada uma pesquisa na Empresa Brasileira de Correios e Telégrafos (ECT) que apresenta características adequadas ao objeto de estudo. A metodologia aplicada foi da pesquisa de campo, do tipo quantitativo. O referencial teórico e a aplicação de análise estatística descritiva contribuíram para o alcance dos objetivos de: (1) avaliar o comportamento dos subfatores que influenciam a Gestão do Conhecimento Estratégico (GCE); (2) avaliar a inter-relação dos subfatores da Gestão do Conhecimento Estratégico quando analisados sob o ponto de vista de uma organização pública; e (3) estabelecer o detalhamento dos subfatores sistêmicos do modelo da Gestão do Conhecimento Estratégico, à luz da Ciência da Informação. A partir dos resultados da pesquisa ficou caracterizada a existência de um inter-relacionamento dos subfatores da GCE, principalmente entre "Contexto" e "Motivação", "Experiência e Liderança" e "Integração e Estrutura de Poder". As principais contribuições da pesquisa para a Ciência da Informação são: (a) constatação do caráter interdisciplinar no estudo da GCE; (b) aprofundamento do estudo da GCE; e (c) avaliação do comportamento dos subfatores da GCE aplicados em um estudo de caso. Foi possível também estabelecer uma associação dos subfatores da GCE sob o enfoque da Ciência da Informação.
\end{abstract}

Palavras-Chave: gestão do conhecimento; gestão do conhecimento estratégico; interdisciplinaridade; análise fatorial; Ciência da Informação.

\begin{abstract}
To evaluate the Knowledge Management Strategy (KMS) research was carried out at the Brazilian Post Office, since such an organization has relevant characteristics in this study. The methodology used was the survey with statistical analysis. The theoretical approach and the application of the descriptive statistical analysis contributed to the achievement of the objectives: (1) evaluate the behavior of variables that influence Knowledge management Strategy (KMS); evaluate inter-relationship of the variables of Knowledge Management Strategy when examined from the point of view of a public organization: (3) establish the detail of the systemic variables from the Knowledge Management Strategy model (design? pattern) by the view of the Information Science. The result of the research showed the existence of an interrelationship of the variables of KMS, especially among "Context" and "Motivation", "Experience and Leadership" and "Integration and Structure of Power". The main contributions of the research to

1 Mestre em Ciência da Informação, Universidade de Brasília. Brasília, DF, Brasil. E-mail: <ken_brasil@yahoo.com>. Recebido em 17/3/2009 e aceito para publicação em 30/9/2009.
\end{abstract}


the Information Science are: (a) evidence (seeing) of the interdisciplinary character Of KMS; (b) deepening of the study of KMS; and (c) evaluation of the behavior of variables applied in a case study. It was also possible to establish a relationship of the variables of KMS under the Information Science.

Keywords: knowledge management; knowledge management strategy; interdisciplinarity; factor analysis; Information Science.

\section{INTRODUÇÃO}

Ensinar, aprender e integrar-se ao mundo do conhecimento são preocupações cada vez mais recorrentes no mundo corporativo, considerando que as empresas estão percebendo que a gestão do conhecimento pode ser um diferencial competitivo nesse mundo competitivo. Segundo Choo (2006), as organizações processam e usam a informação para a criação de significados, construção do conhecimento e tomada de decisão, e o conhecimento organizacional emerge quando esses três modos de usar a informação se conectam em busca de geração de aprendizado e ações. Para Tarapanoff (2006), o grande desafio das corporações é construir um ambiente onde todos possam criar, acessar, utilizar e compartilhar informação e conhecimento. Na Ciência da Informação, a gestão do conhecimento é uma área de interesse de estudo e é uma disciplina que trabalha sistematicamente a informação e o conhecimento, visando ao aumento da capacidade de resposta da empresa ao meio ambiente em que vive (Tarapanoff, 2006).

A Gestão do Conhecimento Estratégico (GCE) foi objeto de estudo de Miranda (2004) que apresentou um modelo de GCE por uma função assim definida: Gestão do Conhecimento Estratégico $=f$ (cognição, tecnologia, cultura organizacional, modelo gerencial e contexto). São cinco fatores compostos de onze subfatores assim distribuídos no Quadro 1:

Quadro 1. Relação dos fatores e subfatores do modelo da GCE proposto por Miranda (2004).

\begin{tabular}{|l|l|}
\hline Fatores & Subfatores \\
\hline Cognição & $\begin{array}{l}\text { (1) Processos Mentais } \\
\text { (2) Experiência } \\
\text { (3) Capacidade de Julgamento }\end{array}$ \\
\hline Tecnologia & $\begin{array}{l}\text { (4) Arquitetura de Tecnologias de Informação e Comunicação (TIC) } \\
\text { (5) Técnicas e Métodos }\end{array}$ \\
\hline Cultura Organizacional & $\begin{array}{l}\text { (6) Motivação } \\
\text { (7) Integração } \\
\text { (8) Compartilhamento }\end{array}$ \\
\hline Modelo Gerencial & $\begin{array}{l}\text { (9) Liderança } \\
\text { (10) Estrutura de Poder, Influência e Autoridade } \\
\text { (1 1) Proposição Clara de Valor }\end{array}$ \\
\hline Contexto & Não há subfatores relacionados \\
\hline
\end{tabular}

\section{OBJETIVOS}

Visando aprofundar o estudo sobre a GCE, foi realizada uma pesquisa para avaliar os subfatores do modelo da GCE descritos no quadro 1 e como eles se comportam quando aplicados na prática de uma organização. $O$ trabalho aborda três objetivos: (1) avaliar o comportamento dos subfatores que influenciam 
a Gestão do Conhecimento Estratégico (GCE); (2) avaliar a inter-relação dos subfatores da Gestão do Conhecimento Estratégico quando analisados sob o ponto de vista de uma organização pública e (3) estabelecer o detalhamento dos subfatores sistêmicos do modelo da Gestão do Conhecimento Estratégico, à luz da Ciência da Informação.

\section{JUSTIFICATIVA}

A principal justificativa para o estudo da Gestão do Conhecimento Estratégico está relacionada à interdisciplinaridade da Ciência da Informação, principalmente com a Ciência da Computação e a Ciência Cognitiva, pois envolvem aspectos das diferentes áreas científicas, conforme descritas por Saracevic (1996).

Choo (2006) caracteriza essa interdisciplinaridade e permite uma abordagem da Gestão do Conhecimento relacionada à Ciência da Informação, ao tratar da busca e uso da informação na construção do conhecimento no qual os processos de informação são administrados, buscando o compartilhamento de informações, a conversão do conhecimento tácito, a experimentação e a migração de conhecimento de outras partes da organização.

O detalhamento dos subfatores da GCE sob a luz da Ciência da Informação e a avaliação da percepção - tanto de estrategistas e como de decisores - das ações relacionadas aos subfatores aplicadas numa organização permitem analisar a Gestão do Conhecimento sob vários aspectos.

A escassez de literatura sobre Gestão do Conhecimento Estratégico também contribui para justificar o aprofundamento desse tema.

\section{A CIÊNCIA DA INFORMAÇÃO E A GESTÃO DO CONHECIMENTO ESTRATÉGICO}

Segundo Moura (2006), a Ciência da Informação tem por objetivo compreender as relações humanas mediadas pela informação e os desdobramentos dessa ação, buscando compreender, do ponto de vista do indivíduo, os aspectos sociais e técnicos envolvidos na ação de produzir, sistematizar, organizar, disseminar e recuperar a informação. $\mathrm{Na}$
Ciência da Informação, a gestão do conhecimento é uma área de interesse de estudo e é uma disciplina que trabalha sistematicamente a informação e o conhecimento, visando ao aumento da capacidade de resposta da empresa ao meio ambiente em que vive (Tarapanoff, 2006).

\section{Gestão do Conhecimento}

Alvarenga Neto (2008) descreve que a GC consolidou-se como uma grande área guarda-chuva que incorpora conceitos da Ciência da Informação, Administração e Ciência da Computação. Envolve atividades como a gestão de documentos, mapeamento de competências, compartilhamento do conhecimento, mapeamento de processos, construção de sentidos, criação de conhecimento, tomada de decisão. Abriga abordagens gerenciais e ferramentas de gestão da inovação, capital intelectual, comunidades de prática, memória organizacional, gestão estratégica da informação, inteligência competitiva e monitoração ambiental. $\bigcirc$ significado de GC confunde-se e remetese à gestão da informação, gestão de recursos informacionais, gestão de ativos intangíveis, aprendizagem organizacional e, por fim, à inovação organizacional, exigindo uma nova forma de pensar a organização. Para Miranda (2004), a gestão do conhecimento "é o processo de criação, captura, assimilação e disseminação do conhecimento tácito extrínseco individual, integrando-o ao conhecimento organizacional, a fim de que seja utilizado como subsídio útil às diversas atividades desenvolvidas no âmbito da organização". Segundo Fleury e Oliveira Jr. (2001), o conhecimento da empresa representa a informação associada à experiência, intuição e valores e é fruto das interações que ocorrem no ambiente de negócios. A gestão do conhecimento deve servir como linha norteadora das ações estratégicas e por isso define-se a gestão estratégica do conhecimento como sendo a tarefa de identificar, desenvolver, disseminar e atualizar o conhecimento estrategicamente relevante para a empresa.

Como produto interdisciplinar, complexo e multifacetado (Alvarenga Neto, 2008), o conhecimento permeia toda a organização e atinge todos os níveis estruturais da empresa: o operacional, o tático e o estratégico. 


\section{Conhecimento Estratégico}

O nível estratégico é reconhecido na administração como o nível do topo da pirâmide, onde estão os principais executivos da organização e onde são tomadas as principais decisões da empresa. É nesse nível que são definidos os objetivos, as políticas e as estratégias da organização, compondo o chamado planejamento estratégico. Para Oliveira (2007), o planejamento estratégico possibilita ao executivo estabelecer o rumo e as estratégias da organização que indicam o caminho para se alcançar os objetivos estabelecidos. A metodologia para implementação das estratégias envolve as seguintes etapas: (1) definição da visão da empresa; (2) definição da missão; (3) avaliação de cenários; (4) estabelecimento das estratégias; (5) estabelecimento de estratégias alternativas; (6) escolha das estratégias a serem implementadas; (7) implementação das estratégias; e (8) avaliação das estratégias implementadas (Oliveira, 2007).

Informações e conhecimentos no nível estratégico são fundamentais no processo de planejamento estratégico quando do estudo de cenários (Oliveira, 2007), da avaliação da concorrência e dos movimentos competitivos (Porter, 1986), ou da utilização do balanced scorecard pelas organizações orientadas para a estratégia, visando à preparação do planejamento estratégico (Kaplan; Norton, 2000).

Miranda (2004) define conhecimento estratégico como sendo um "tipo de conhecimento organizacional, que abarca saberes relacionados ao planejamento, à descrição, ao impacto, à predição, à avaliação e à geração de estratégias, sendo formado por vertente explícita - as informações estratégicas e as de acompanhamento - e a tácita - o conhecimento acumulado por estrategistas e decisores nos processos de formulação e decisão estratégicas".

Fazer a gestão desse conhecimento estratégico torna-se importante para o processo de planejamento estratégico, uma vez que esse conhecimento pode ser transferido, disseminado e utilizado ciclicamente na organização.

\section{Gestão do Conhecimento Estratégico}

Segundo Miranda (2004), a Gestão do Conhecimento Estratégico está relacionada ao conhecimento acumulado por estrategistas e decisores nos processos de formulação e decisão estratégicas e abarca saberes relacionados ao planejamento, à descrição, ao impacto, à predição, à avaliação e à geração de estratégias, sendo formado por informações estratégicas e de acompanhamento. Para o autor, o modelo da GCE pode ser representado da seguinte forma: $G C E=f$ (cognição, tecnologia, cultura organizacional, modelo gerencial, contexto).

São cinco fatores formados por subfatores

\section{a. Fator: Cognição}

i. Processos mentais (uso do bom senso).

ii. Experiência (uso do saber prático).

iii. Capacidade de julgamento (uso do discernimento e da razão).

b. Fator: Tecnologia

i. Arquitetura de TIC (disponibilidade de recursos de TIC - hardware e software).

ii. Técnicas e métodos (uso de técnicas e métodos sistemáticos).

c. Fator: Cultura Organizacional

i. Motivação (estímulo para realizar as tarefas).

ii. Integração (companheirismo e harmonia em equipe).

iii. Compartilhamento (permuta de conhecimento).

d. Fator: Modelo Gerencial

i. Liderança (postura do decisor).

ii. Estrutura de poder, influência e autoridade (alto prestígio e exercício de influência).

iii. Proposição clara de valor (capacidade de difundir os valores).

e. Fator: Contexto (tempestividade e oportunidade de adoção de estratégia).

\section{Subfatores da GCE e a Ciência da informação}

\section{Processo Mental}

Percebe-se, na prática, que o homem tem usado com frequência a experiência, a criatividade, a intuição e o bom senso no seu dia-a-dia. São processos mentais 
utilizados quando se trata de trabalhar com a informação. Na linha da Ciência da Informação, por exemplo, ao estudar a arquitetura da informação na web, Rosenfeld e Morville (2002) descrevem que a arte da arquitetura da informação é saber que pode correr riscos em colocar as idéias em prática, mas acertando com a ajuda da intuição e do bom senso de cada profissional. Esses processos mentais são bastante utilizados no mundo corporativo, principalmente no processo de tomada de decisão que envolve invariavelmente um pensamento contínuo de escolha entre o uso da razão ou da emoção. Mesmo sabendo que a emoção pode alterar sensivelmente a decisão a ser tomada, o indivíduo a usa em certas circunstâncias. Esse contexto retrata um estresse cognitivo no processo mental, porque a tomada de decisão é baseada em análise de informações. Segundo Trouillet (1998), a intuição decorre de um processo mental que computa inúmeras regras, fatos e variáveis ao longo do tempo com o objetivo de avaliar, planejar e agir.

Tem-se como "processo mental", na GCE, o uso do bom senso na decisão e na formulação de estratégias em contraposição a informações documentais, orais, visuais ou outras que recebe ou a que tem acesso. (Miranda, 2004). Para o caso da GCE, o bom senso é retratado como um processo intuitivo. Para Nonaka e Takeuchi (1997) insights, intuições e palpites altamente subjetivos encontram-se no âmago da criação do conhecimento. No âmbito do conhecimento estratégico, o uso da informação no processo de planejamento e formulação de estratégias é permanente. Em geral, ao lidar com decisões estratégicas, estrategistas e decisores trabalham mais a razão do que a emoção, mas o uso do bom senso e da intuição também é frequente, considerando que o homem é limitado no uso da racionalidade. A capacidade limitada de processamento de informações é retratada por Robbins (2004), ao descrever que é impossível assimilar e compreender todos os dados necessários para a perfeita tomada de decisão, e por Pereira e Fonseca (1997), quando descrevem a incapacidade do homem de analisar todas as alternativas e consequências de uma decisão.

Outro fator que influencia o uso do bom senso na tomada de decisão é a indisponibilidade ou falta de informações (Brookes, 1980 ; Mintzberg, 2004). Castro e Abreu (2006) lembram que os indivíduos nunca terão perfeito conhecimento de todas as variáveis ambientais que podem influenciar determinada decisão, assim como não é possível levar em conta todas as alternativas possíveis quando se toma uma decisão. Se a decisão tiver que ser tempestiva, o decisor pode optar por usar o bom senso ou a intuição.

Para Goleman, Boyatzis e McKee (2002) a intuição representa a capacidade essencial de a liderança aplicar não só os conhecimentos técnicos, mas também a experiência de vida à tomada de decisão. Segundo Siqueira (2002), uma atitude mental centrada apenas no racionalismo dificulta a capacidade de o indivíduo enfrentar o inesperado, como é o caso de decidir com base em cenários futuros. $\bigcirc$ trabalho por meio de previsões e visão de futuro tende a envolver o uso do bom senso na tomada de decisão estratégica. Diante desse cenário, fica evidente que trabalhar as estratégias simplesmente por meio da racionalidade das informações factuais não é o melhor caminho.

$\mathrm{Na}$ GCE, estrategistas e decisores devem conciliar a razão e a intuição no gerenciamento das estratégias organizacionais. As variações nos sentimentos fazem com que o indivíduo questione suas próprias certezas. Por isso, o homem equilibra o uso do pensamento crítico com o uso do bom senso, misturando a razão e a emoção para a tomada de decisão.

\section{Experiência}

As situações vividas pelo homem são registradas pela mente humana, ficando algumas percepções retidas na memória e outras sendo simplesmente apagadas. Essa vivência ajuda o homem a utilizar tais experiências na hora de tomar decisões. Todos os conhecimentos acumulados devem fazer parte da experiência de cada um. Para Davenport e Prusak (1998), o conhecimento é uma mistura de experiência, valores, informações e percepções que proporciona uma estrutura para a avaliação e incorporação de novas experiências e novas informações. O conhecimento é fator chave para o processo de formulação de estratégias. A criação de uma estratégia requer uma síntese natural do futuro, do presente e do passado. Para Mintzberg (1998), embora a palavra estratégia tenha uma associação com o futuro, ela não pode ser formulada sem se conhecer o presente e o passado. Esse passado não apenas representa a história da organização, mas também a experiência trazida pelos estrategistas e decisores dentro do contexto vivido pela empresa. 
Para Figueiredo (2005), um bom programa de gestão do conhecimento ocorre quando se reconhece o valor da experiência.

Cyert e March apud Almeida (2006) tratam a memória como elemento influenciador no processo de tomada de decisão. A memória da organização representa experiências passadas registradas, que afetam as regras de decisão. No modelo da GCE, Miranda (2004) considera a experiência como um subfator da cognição e a relaciona ao saber prático acumulado pelos estrategistas e decisores ao longo do seu contato profissional com as atividades relacionadas à formulação e/ou decisão estratégica.

A experiência é um fator chave no processo de formação e decisão estratégica, mas nem sempre é valorizada no mundo corporativo. Siqueira (2002) lembra que as empresas brasileiras dispensam a experiência e a capacidade dos profissionais altamente qualificados por puro preconceito contra aqueles que passam dos 40 ou 50 anos de idade. As organizações promovem a renovação dos quadros de pessoal, sem levar em conta a razão e a maturidade, imprescindíveis para a tomada de decisão corretas e responsáveis. Esse retrato é uma realidade em várias empresas que promovem a reengenharia ou o downsizing, dispensando geralmente pessoas experientes e antigas devido à possível falta de motivação ou redução de custo.

Wright, Mark e Parnell (2000) descrevem que as decisões estratégicas são caracterizadas por risco e incerteza consideráveis e que as mudanças rápidas e amplamente imprevisíveis podem transformar rapidamente os planos estabelecidos em estratégias ineficazes. Assim, a experiência dos estrategistas e decisores torna-se fator essencial para que todas as variáveis sejam consideradas no tratamento das informações estratégicas. Entretanto nem sempre todas as informações estão disponíveis. Ansoff (1990) lembra que, no momento de formulação de estratégias, não é possível enumerar todas as possibilidades de projetos a serem identificadas e, por isso, as estratégias são formuladas com base em informações agregadas, incompletas e incertas, e isso exige grande experiência dos estrategistas. A experiência do estrategista também é determinante quando há a necessidade de se corrigir um rumo e mudar as estratégias anteriormente definidas. As necessidades de mudança estratégica podem ocorrer por decisões erradas ou planejamento equivocado das ações. Reconhecer o erro e saber mudar têm uma forte relação com a experiência. Para Bossidy e Charam (2005), cometer erros é inevitável, mas bons líderes admitem, aprendem com eles e criam ao longo do tempo um processo de tomada de decisão com base na experiência. $O$ aprendizado ocorre quando as pessoas consideram a experiência, pois ela desenvolve força emocional e amplia a capacidade pessoal. Castro e Abreu (2006) acreditam que, à medida que a organização atinge a maturidade, o processo decisório apresenta características provenientes do histórico de decisões anteriores, do maior conhecimento sobre o comportamento dos atores do ambiente externo, do fluxo de informação da organização, ou seja, de experiências vividas e adquiridas ao longo do tempo.

\section{Capacidade de Julgamento}

A capacidade de julgamento é fundamental quando se trata de usar informações e conhecimentos no processo de decisão. Considerando que o conhecimento forma a base para a compreensão de diversos fatores relacionados ao mundo social, empresarial e pessoal, Wersig (1993) apud Renault; Martins (2007) considera que a Ciência da Informação deve buscar compreender o processo de transformação a partir do conhecimento que precisa ser empírico, provado e pragmático. Stacey (2000) diz que a palavra racionalidade está relacionada ao comportamento e à decisão associados à realidade, fatos e objetivos, em que a decisão seja razoável ao invés de absurda. A irracionalidade envolve fantasia e escolhas sem razões lógicas e objetivas. $\mathrm{O}$ uso da razão tem por objetivo reduzir as incertezas envolvidas na tomada de decisão. Para Bossidy e Charam (2005), a capacidade de julgamento é fundamental para qualquer líder. Qualquer decisão equivocada pode conduzir erroneamente os rumos estratégicos da organização. Choo (2006) destaca que a tomada de decisão da organização é racional e, mesmo que seus membros tenham sua racionalidade limitada, a empresa é intencionalmente racional.No modelo da GCE, o subfator capacidade de julgamento está relacionado ao uso do discernimento e da razão nas atividades relacionadas à formulação e/ou decisão estratégicas (Miranda, 2004). O trabalho dos estrategistas e decisores envolve a avaliação das informações advindas do estudo do ambiente de negócios e o uso da razão visa diminuir o risco da decisão tomada. 
homem é o principal responsável pela formulação e busca de soluções estratégicas, mas a capacidade de julgamento do ser humano é limitada pelas informações e conhecimento que possui. Por isso, a organização deve buscar mecanismos para reduzir as incertezas, fornecendo informações suficientes para facilitar a capacidade de julgamento do estrategista.

\section{Arquitetura de Tecnologia da Informação e Comunicação (TIC)}

A chegada da tecnologia mudou o cotidiano das pessoas. No modelo da GCE, o subfator "arquitetura de TIC", representa a disponibilidade de recursos de hardware e software, necessários e suficientes, voltados para a busca, o tratamento e a disponibilização de informações no âmbito das atividades relacionadas à formulação e/ou decisões estratégicas (Miranda, 2004). Para Laudon e Laudon (1999), a dimensão "tecnologia" dos sistemas de informação está relacionada a software e hardware, além da tecnologia de armazenamento de dados e comunicação.

Senge (1998) foi simples e direto ao descrever que a tecnologia ajuda as pessoas a fazer o que sempre fizeram, porém mais depressa. Diversos estudiosos da Gestão do Conhecimento e da Ciência da Informação têm demonstrado a interdisciplinaridade, principalmente com a Ciência da Computação, em vários estudos. Terra (2001), por exemplo, delineia um modelo de gestão do conhecimento em sete dimensões, sendo uma delas os sistemas de informações que são utilizados para oferecer aos principais executivos acesso a vários tipos de informação.

Araújo (1995) trata dos Sistemas de Recuperação da Informação, cujo objetivo é dar acesso às informações contidas em documentos e constituem a "memória humana registrada". A associação entre a tecnologia da informação e a gestão do conhecimento envolve o compartilhamento da informação ou conhecimento por meio desses sistemas de informação. Para Figueiredo (2005), o sucesso da gestão do conhecimento, dos negócios e a própria empresa dependem da escolha adequada e coerente das plataformas de hardware e software e da adoção de ferramentas e soluções de TI. Segundo Teixeira Filho (2000), a tecnologia da informação bem usada passa a ser um recurso estratégico para qualquer organização e a aplicação eficiente e eficaz torna-se fator crítico de sucesso. $O$ 'Brien (2001) retrata a realidade, ao descrever que a tecnologia da informação já é parte integrante do dia-a-dia das empresas e está redefinindo os fundamentos dos negócios. Santiago Jr. (2004) destaca que a tecnologia da informação tem-se tornado um fator estratégico de competitividade e sobrevivência organizacional. Hoje, o desempenho organizacional está invariavelmente relacionado ao uso efetivo de sistemas de informações bem estruturados. Um sistema confiável, funcional, útil e eficiente que contenha informações relevantes que atendam e satisfaçam as necessidades do decisores e estrategistas é fundamental para o processo de elaboração de um planejamento estratégico e para a gestão do conhecimento estratégico.

\section{Técnicas e Métodos}

No processo de planejamento estratégico, estrategistas e decisores utilizam constantemente métodos e técnicas da administração para facilitar o trabalho de pensar estrategicamente. No modelo da GCE, Miranda (2004) descreve o subfator "técnicas e métodos" como a utilização sistemática e efetiva de ferramental teórico-prático que se constitua de verdadeira metodologia de trabalho, incluindo técnicas e métodos desenvolvidos para o trabalho das atividades de formulação e de decisão estratégicas. Várias técnicas e métodos úteis para a gestão do conhecimento estratégico são destacadas pelos diversos autores, como, por exemplo, a matriz BGC (Ansoff, 1993), séries temporais, previsão por julgamento, técnica Delphi e cenários múltiplos (Wright; Mark; Parnell, 2000), análise de SWOT (Araújo Junior, 2005), a teoria dos jogos (Ghemawat, 2000), as cinco forças de Porter (Porter, 1986). Com relação direta à gestão do conhecimento, Miranda e Gaspar (2006) relacionam diferentes técnicas de elicitação do conhecimento que podem ser utilizadas para formulação estratégicas. São mais de quarenta e cinco técnicas, das mais simples às mais complexas, incluindo as mais conhecidas e praticadas no mundo corporativo como as entrevistas e o brainstorming. Entrevistar especialistas de mercado, discutir e analisar opiniões em grupo, analisar casos de outras organizações e simular cenários possíveis que retratem o ambiente da empresa são técnicas usuais de mercado utilizadas pelas organizações para as ações estratégicas. 
Atualmente, uma das técnicas mais utilizadas pelas organizações para o desenvolvimento do planejamento estratégico é o BSC, ou Balanced Scorecard. O BSC traduz a missão e as estratégias das empresas num conjunto abrangente de medidas de desempenho que serve de base para um sistema de medição e gestão estratégica. Essa ferramenta alinha as equipes executivas, as unidades de negócios, os recursos humanos, a tecnologia da informação e os recursos financeiros na estratégia da organização (Kaplan ; Norton, 2000).

Como estudioso da Ciência da Informação, Alvarenga Neto (2008) também trata o BSC, assim como - Valor Econômico Agregado (EVA) como uma ferramenta do conhecimento, sendo o BSC útil como estrutura para a ação estratégica. A variação nas técnicas e nomenclaturas é grande, mas muitas vezes apresentam o mesmo objetivo, alterando apenas a forma de desenvolver as técnicas. $\bigcirc$ importante é que essas ferramentas têm ajudado os estrategistas e decisores na formulação das estratégias das empresas.

\section{Motivação}

Percebe-se, na prática, que pessoas motivadas geram melhores resultados. $\bigcirc$ comportamento e a atitude das pessoas motivadas tendem a ser mais positivos e a focar mais o alcance dos objetivos traçados. Robbins (2004) define que a motivação consiste na disposição para fazer alguma coisa e está condicionada à capacidade de essa ação satisfazer uma necessidade do indivíduo. Existem diversas teorias da administração relacionadas à motivação, como a teoria da hierarquia das necessidades de Abraham Maslow, a teoria X e a teoria Y de Douglas McGregor, a teoria dos dois fatores de Frederick Herzberg, a teoria das necessidades de David McClelland e a teoria da expectativa de Victor Vroom (Robbins, 2004). Essas teorias e análise de outros estudiosos levam à reflexão sobre alguns pontos relacionados à motivação, como o reconhecimento das diferenças individuais, o estabelecimento de metas e objetivos desafiadores e atingíveis, a necessidade de recompensar os indivíduos conforme desempenho e avaliação da percepção e o senso de justiça envolvido no sistema de trabalho da organização (Kaplan ; Norton, 1997; Sveiby, 1997).

A interdisciplinaridade da Ciência da Informação traz cada vez mais estudos relacionando os aspectos humanos à informação e ao conhecimento. Ribeiro (2004) descreve a importância da motivação no ambiente bibliotecário, onde os documentos devem estar bem organizados para satisfazer as necessidades informacionais de seus usuários. Bianchi (2007), por sua vez, descreve a importância da motivação do indivíduo para a gestão do conhecimento, pois pessoas motivadas contribuem melhor para o desenvolvimento do acervo de conhecimento da organização. A gestão do conhecimento é efetiva quando há múltiplas competências dos indivíduos, que devem estar envolvidos e motivados com o processo de busca, construção, uso e, principalmente, compartilhamento da informação. Para Figueiredo (2005), a motivação é um ingrediente essencial na gestão do conhecimento, pois sem ela não há aprendizado, não há criação de conhecimento e não há compartilhamento. Segundo Saracevic (1996), a informação está associada à cultura, ao trabalho ou à solução de um problema e envolve motivação e intencionalidade. Para Caldas (2007) a informação deve ser considerada por pesquisadores como relacionada a uma situação, uma tarefa ou um problema concreto, que envolve a motivação do usuário e sua intencionalidade associada ao contexto social, à cultura e ao trabalho. No modelo da GCE o subfator "motivação" está relacionado ao estímulo que os estrategistas e decisores demonstram ao desenvolver suas atividades dentro da organização (Miranda, 2004). Na gestão do conhecimento estratégico, o foco da motivação está na ação do planejamento estratégico, envolvendo o estabelecimento de objetivos e metas voltadas para a estratégia organizacional. Para Kotter (1999, o líder tem o papel de motivar e inspirar as pessoas, e a motivação representa a "injeção de ânimo" para que elas estejam preparadas para superar as barreiras que surgirem pela frente.

Hiam (2004) destaca algumas ações que ajudam a motivar as pessoas:

- concentrar nos pontos fortes e potenciais das pessoas;

- encontrar coisas específicas para elogiar ou recompensar cada pessoa;

- encorajar os colaboradores a tentar fazer as coisas com vontade;

- reconhecer o progresso e os resultados e

- comemorar o sucesso. 
Não importa a forma de motivação. $\bigcirc$ importante é que estrategistas e decisores tenham energia e entusiasmo para executar suas atividades e estejam motivados para obter um desempenho eficiente e adequado às ações estratégicas. Em geral, pessoas motivadas desempenham melhor suas funções e se dedicam mais ao trabalho, tendendo a aumentar sua produtividade.

\section{Integração}

Assim como a motivação, a integração das pessoas no ambiente corporativo ajuda a obtenção de melhores resultados. Uma equipe integrada e ativa, que trabalha em harmonia, tem maiores chances de apresentar melhores resultados. Para Bossidy e Charam (2005), a harmonia da equipe leva a organização a melhores resultados e a sincronização é essencial para energizar a organização em busca da excelência. A sincronização significa que todas as partes da organização têm premissas comuns e um entendimento uniforme de como as ações devem acontecer. Para Kaplan e Norton (1997), as empresas devem trabalhar seus colaboradores de forma a agregarem valor pelo que sabem e pelas informações que podem fornecer e, por isso, devem investir, gerenciar e explorar o conhecimento de cada um. Segundo Kotter (1999), o trabalho em equipe torna-se eficiente quando há confiança entre seus membros. Ações corporativas sociais e culturais podem ajudar a integrar pessoas, sendo o importante o aumento do grau de confiança e da compreensão mútua, e, consequentemente, a integração entre essas pessoas.

Pesquisadores da Ciência da Informação também têm considerado a integração nos seus estudos. Marchiori (2002), por exemplo, descreve a importância do mapeamento e da integração das unidades, pessoas e fluxos de informação na organização como parte da gestão integral dos recursos informacionais.

Para Valentim e Gelinski (2005), as empresas estão cada dia mais criando espaços físicos e ambientes propícios para as pessoas interagirem entre si, visando à integração entre os indivíduos e o desenvolvimento da criatividade de cada um. Takeuchi e Nonaka (2008) chamam esse espaço criativo de ba, que também representa um local existencial onde os participantes partilham seu contexto e criam novos significados por meio de interações, o que facilita a integração entre as pessoas.

Na GCE, o subfator "integração" está relacionado à facilidade com a qual a equipe de estrategistas se relaciona e ao nível de companheirismo e amizade entre o time, enquanto membros do grupo de formulação de estratégias (Miranda, 2004).

A integração deve ocorrer nos sentidos vertical e horizontal, de forma que haja integração entre os líderes e liderados, bem como entre os próprios líderes. O importante é que todas as pessoas competentes da organização capazes e dispostas a aprender e a agregar valor para a organização possam trabalhar integradas num mesmo objetivo. Bennis (1998) considera que os líderes devem desenvolver uma arquitetura social de forma que as pessoas mais brilhantes trabalhem em equipe e aprendam a utilizar a criatividade. Para Bossidy e Charam (2005), os líderes devem discutir as questões de negócios e de organização dentro de um contexto de grupo, pois todos aprendem. Tratar questões desafiadoras coletivamente aumenta a capacidade das pessoas e amplia o aprendizado individual e organizacional.

\section{Compartilhamento}

Compartilhar conhecimento é uma atividade complexa, tendo em vista a competitividade existente entre as pessoas. Por isso, o ato de compartilhar pode ser considerado como parte da cultura organizacional de uma empresa. O compartilhamento de conhecimento ocorre quando as pessoas estão interessadas em ajudar umas às outras a aprender. $\mathrm{Na}$ linha da organização que aprende, Senge (1998) defende que compartilhar conhecimento é criar processos de aprendizagem.

Na GCE, Miranda (2004) relaciona o subfator "compartilhamento" à facilidade com a qual a equipe de estrategistas permuta conhecimentos e experiências, indicando o nível de conversão do conhecimento (socialização, externalização, internalização e combinação) e o grau de competitividade entre os estrategistas. $\bigcirc$ compartilhamento de informação e conhecimento, principalmente no nível estratégico, é fundamental, tendo em vista que as decisões tomadas nesse nível influenciam no futuro da organização. 
O compartilhamento do conhecimento pressupõe um processo de comunicação, envolvendo troca de informações e mensagens entre as pessoas. No estudo da documentação, por exemplo, Otlet (1934) apud Santos (2006) relaciona que um dos objetivos da documentação organizada é que as informações documentadas devem ser colocadas à disposição do maior número de pessoas. $\bigcirc$ ato de disponibilizar informações de forma escrita permite que ocorra uma forma de compartilhar conhecimento a qual Nonaka e Takeuchi (1997) definem como internalização, no modelo de conversão do conhecimento, onde se transforma o conhecimento explícito em conhecimento tácito. $\bigcirc$ compartilhamento do conhecimento, seja tácito ou explícito, deve ocorrer em todos os níveis organizacionais. Prahalad (1998) defende que as empresas precisam ter uma aspiração amplamente compartilhada, envolvendo, inclusive, a geração mais jovem da empresa em vez de apenas a alta administração. $\bigcirc$ compartilhamento de informações e conhecimentos ocorre com mais facilidade quando há uma formação de rede de relacionamento que permite a formação das redes de conhecimento. Para Tomaél (2008), são características das redes de conhecimento: (1) movimentam-se pelo compartilhamento da informação e pela construção do conhecimento; (2) possibilitam o desenvolvimento de novas idéias e processos, decorrentes da conversação e troca de informações; (3) reúnem transeuntes que se interessam em compartilhar sua especialidade. Terra (2001) relaciona o compartilhamento com a tecnologia, ao descrever que o compartilhamento de informações e conhecimento é facilitado pelo uso de sistemas de informação, que vincula a tecnologia da informação com a gestão do conhecimento. O sucesso da GCE depende do compartilhamento de informações e conhecimento e o ser humano é o principal personagem do processo. Na GCE as informações e o conhecimento devem ser tratados de forma compartilhada e segura, para que decisores e estrategistas possam formular adequadamente as estratégias, definir bem as metas e tomar as decisões de forma adequada.

\section{Liderança}

Liderar significa lidar, conduzir e gerenciar pessoas de forma que todas estejam unidas e focadas num mesmo objetivo. Para Wright, Mark e Parnell
(2000), a liderança envolve a capacidade de garantir a cooperação dos outros na realização de um objetivo. Segundo Bennis (1998), o grande desafio dos líderes é liberar a capacidade mental das suas organizações, encorajando as pessoas a trabalharem em equipe e utilizarem suas criatividades. Eles devem assegurar também que a organização esteja sendo constantemente reinventada. A liderança é citada, no âmbito da Ciência da Informação, por Miranda (1993), ao descrever sua importância no ambiente bibliotecário, quando trata a relação da informação e do conhecimento com o desenvolvimento de serviços bibliotecários, e também por Marchiori (2002), quando aborda o trabalho do gestor da informação e no relacionamento interpessoal para uso inteligente da informação. Davenport e Prusak (1998), ao citar a liderança, descrevem as equipes de informação, que devem ter um entendimento político associado à habilidade para exercê-la.

Na GCE o subfator "liderança" está relacionado à postura do decisor - transmitindo motivação, segurança, apoio - junto à equipe de estrategistas, à definição de limites de ação e à capacidade de tomar decisões em situações complexas, indicando o grau de comprometimento com a estratégia formulada e a decisão estratégica a ser tomada (Miranda, 2004). Liderança é uma característica chave que estrategistas e decisores devem ter para o sucesso de uma organização, pois o líder encoraja os membros da organização a concentrar seus esforços na implementação das estratégias. Segundo Pereira e Fonseca (1997), o líder motiva, desperta admiração e deixa marcas na organização em virtude das decisões que toma.

Estudiosos discutem diversas características que o líder deve apresentar:

- Atitude e Foco no Objetivo - uma das tarefas do líder é agir e executar. O líder deve estar comprometido de corpo e alma e estar envolvido pessoal e profundamente no negócio (Bossidy; Charam, 2005);

- Humildade e Empreendedorismo - o líder deve estar preparado para mudanças, pois o sucesso do passado não tem relação com o sucesso do futuro. É necessário trabalhar a equipe como um time e ter a postura de um empreendedor (Hammer, 1998). São poucos líderes que possuem humildade para se colocar no papel de aprendiz (Senge, 1998); 
- Princípios - os líderes que valorizam os princípios mais do que valorizam suas empresas serão aqueles que alcançarão o sucesso, pois construirão suas vidas e organizações em torno desses princípios (Covey, 1998).

Hiam (2004) também relaciona aspectos que o líder deve apresentar:

- ficar calmo e deixar o grupo trabalhar;

- confiar nas pessoas para trazer à tona o melhor que elas têm e

- resolver quebra-cabeças, fazer perguntas e exercitar o cérebro.

Na gestão do conhecimento estratégico, estrategistas e decisores devem apresentar as características de liderança de forma a transmitir motivação, segurança e apoio aos demais membros do grupo, além de disseminar valores, provocar mudanças e catalisar o comprometimento de todos, de forma que os objetivos estratégicos possam ser traçados e alcançados.

\section{Estrutura de Poder}

Toda organização apresenta uma estrutura específica, compatível e inerente à sua atividade de negócios. A função principal do desenho estrutural é integrar e unir as partes que muitas vezes podem ter pensamentos, comportamentos e tendências diferenciadas. Um dos objetivos de uma estrutura é estabelecer determinada ordem no ambiente. Segundo Wright, Mark e Parnell (2000), a estrutura organizacional refere-se à maneira como os indivíduos são agrupados e aos modos como as tarefas e responsabilidades são alocadas às pessoas. São designadas as relações formais de autoridade e o número de níveis de hierarquia. A quantidade de níveis hierárquicos pode facilitar ou dificultar o andamento dos processos internos, assim como influenciar nas decisões estratégicas da empresa. É importante que a estrutura seja compatível com estratégia empresarial, promova a coordenação entre as partes e permita o agrupamento adequado das atividades.

Ao tratar da Ciência da Informação e da Gestão do Conhecimento, Takeuchi e Nonaka (2008) destacam que a hierarquia é uma estrutura eficiente para adquirir, acumular e explorar novos conhecimentos por meio da combinação e da internalização. É preciso ter estruturas organizacionais que fomentem relacionamentos sólidos e colaboração eficazes.

Na GCE, Miranda (2004) define que o subfator "estrutura de poder, influência e autoridade" está relacionado à postura do decisor frente a outros decisores dentro e fora da organização, estando tal fator relacionado à projeção pessoal do decisor - suas características pessoais (personalidade, estilo de vida etc.) -, bem como à sua capacidade de influência no contexto da tomada de decisão estratégica. Trata-se da influência do "personalismo" no processo de tomada de decisão. Quando se trata de conhecimento estratégico, a estrutura de poder pode facilitar o acesso a determinadas informações, bem como pode facilitar o compartilhamento de conhecimento entre estrategistas e decisores. Segundo Wright, Mark e Parnell (2000), o poder representa a capacidade de influenciar o comportamento dos outros e pode ser utilizado de várias formas, como por meio da perícia, do carisma, da permuta e do controle sobre a informação:

- Poder por meio de perícia - ocorre quando uma pessoa possui maior conhecimento sobre uma determinada situação.

- Poder por meio do carisma - ocorre quando uma pessoa possui magnetismo pessoal, entusiasmo, crenças bem estabelecidas e poder de atração

- Poder pela permuta - ocorre quando um indivíduo faz um favor a alguém de modo, que esta pessoa tenha um senso de obrigação para com ele.

- Poder por meio do controle da informação - ocorre quando alguém tem acesso privilegiado a importantes informações e controla sua distribuição para os outros a fim de influenciar o comportamento das pessoas.

A coalizão entre estrategistas e decisores pode influenciar o ambiente e as estratégias, dependendo do equilíbrio ou desequilíbrio existente entre as partes e no poder que elas exercem. A estrutura de poder oferece aos principais líderes e estrategistas da organização poderes para realizar a gestão estratégica da empresa de forma a controlar as pessoas e decidir o futuro da organização.

\section{Proposição Clara de Valor}

O processo de planejamento estratégico envolve invariavelmente, além do estabelecimento das 
estratégias, a definição da missão, da visão e dos valores da organização. Após essa definição, tais valores são geralmente divulgados e disseminados para todas as pessoas para que possam compreender o propósito da empresas. $O$ entendimento dos valores deve ser uniforme e claro. À luz da Ciência da Informação, Vanti (1999) e Miranda (1993) retratam a importância de as bibliotecas, por exemplo, terem uma visão definida e compartilhada e que seria possível a biblioteca chegar a uma visão própria, exclusiva, orientada à satisfação dos usuários e ao atendimento de suas necessidades. Para Tarapanoff (2004), não somente a visão, missão, crenças e valores institucionais fazem parte do conhecimento cultural da empresa, mas também o processo de gestão da informação e gestão do conhecimento deve ter vínculo com as estratégias e missão da organização.

Miranda (2004) definiu no modelo da GCE o subfator "proposição clara de valor", relacionado ao fator "Gerencial", que representa a capacidade de o decisor difundir entre os estrategistas a missão, a visão, os objetivos, as políticas e as tendências em termos de estratégias adotadas pela organização. Para Oliveira (2007), é necessário que o principal executivo conceitue a missão da empresa, crie uma visão de futuro, defina os valores e os dissemine, para que a orientação estratégica apresente resultados desejados.

A comunicação dos valores organizacionais é fundamental para que a empresa alcance seus objetivos. Segundo Kotter (1999), a comunicação pode ocorrer por meio de reuniões, discursos da diretoria e envio de memorandos, boletins e comunicados.

Prahalad (1998) descreve que as empresas precisam ter uma intenção estratégica, ter uma meta que seja clara e ter a obsessão de vencer, além de precisar engajar o máximo de pessoas possíveis. Nessa linha, estrategistas e decisores devem dominar a missão, a visão, objetivos e as metas, e devem divulgar e disseminar os valores pela organização.

Transmitir os valores estratégicos não é uma tarefa fácil, pois eles devem alcançar todos os níveis da organização. Segundo Kaplan e Norton (1997, 2000), o alinhamento da organização a uma visão compartilhada com uma direção comum é um processo demorado e complexo. Por isso, é essencial que a organização promova uma visão estratégica estruturada e compartilhada e que busque meios efetivos de comunicar a estratégia, de forma que todas as pessoas possam entender como suas atividades contribuem para a realização da estratégia global.

\section{Contexto}

Quando se trata de conhecimento estratégico, toda organização necessita avaliar o contexto em que se encontra para definir suas estratégias em busca da sobrevivência no mercado. Segundo Moresi (2001), a organização é um sistema aberto, mantendo transações e intercâmbio com seu ambiente, e tudo o que ocorre externamente no ambiente influencia internamente $o$ que ocorre na organização. As organizações vivem num ambiente dinâmico constituído de condições tecnológicas, legais, políticas, econômicas, demográficas, ecológicas, sociais e culturais que influenciam as ações e o ambiente interno operacional. Para Pereira e Fonseca (1997), os fatores que existem fora do eixo de atenção do decisor, mas que são importantes por dar sentido aos acontecimentos e servir de base para as decisões, representam e formam o chamado contexto. A percepção desse ambiente é importante devido às mudanças do mercado e, por isso, é preciso prestar atenção em coisas que antes passavam despercebidas, a fim de se buscar a informação relevante para a situação vivida. Na GCE, o fator "contexto" representa a tempestividade e oportunidade de adoção de estratégias, de acordo com a situação da empresa (Miranda, 2004). A gestão do conhecimento estratégico envolve invariavelmente informações relacionadas a aspectos políticos, legal, econômicos, tecnológicos e sociais, além das informações setoriais envolvendo compradores, fornecedores, competidores e mercado. Segundo Wright, Mark e Parnell (2000), as informações macroambientais afetam qualquer organização, influenciando direta e poderosamente o planejamento estratégico da organização. As empresas vivem num ambiente competitivo de constantes mudanças e as informações e o conhecimento dos ambientes interno e externo que circundam essas organizações são fundamentais para os estudos do planejamento estratégico. De acordo com Moresi (2001), a aquisição de informações no ambiente externo deve estar presente no cotidiano das empresas, pois esse monitoramento ambiental é útil para os planejadores, visando combater as incertezas estratégicas. Algumas informações são importantes para avaliar o contexto e o ambiente organizacional em que 
a empresa se encontra: PIB, inflação, juros e outros indicadores econômicos, para avaliar o cenário econômico; tecnologia existente e disponível, para avaliar o cenário tecnológico; regulamentações, legislações e proteção ao consumidor, para avaliar o cenário político-legal; o estilo de vida do consumidor, a educação, meios de comunicação e impacto ecológico, para avaliar o cenário sociocultural; o crescimento da população, as migrações, a estrutura familiar e outros indicadores demográficos, para avaliar o cenário demográfico (Oliveira, 2007).

A avaliação do contexto é importante, pois não existe um modelo único ou um padrão estratégico a ser adotado por qualquer empresa. Cada um enfrenta um ambiente diferenciado. Porter (1998) descreve que um dos grandes erros que muitas empresas cometem reiteradamente é tentar adotar uma estratégia universal. Avaliar o contexto de cada mercado é fundamental, pois, por exemplo, se todas as empresas tentarem obter a maior fatia de mercado, o resultado será uma batalha destrutiva em que dificilmente haverá um vencedor. Dentro desse ambiente competitivo, Castro e Abreu (2006) afirmam que a inteligência competitiva tem sido utilizada para suportar decisões táticas e estratégicas em todas as áreas funcionais de uma organização, e a avaliação do contexto organizacional é a base para o estudo da IC.

Sem dúvida as estratégias devem ser formuladas com base no contexto em que cada empresa se encontra. A competitividade está cada vez maior e o ambiente competitivo varia conforme o mercado de atuação. Mercados diferentes exigem estratégias diferentes.

\section{METODOLOGIA}

A pesquisa realizada na Empresa Brasileira de Correios e Telégrafos - ECT - foi de natureza descritiva com o emprego de metodologia quantitativa, cujo objetivo é o estabelecimento de relações entre variáveis (Gil, 2002). A pesquisa ocorreu em duas fases, por meio de pesquisa de campo com aplicação de questionário estruturado.

A pesquisa dos subfatores da GCE obteve 254 respostas válidas dos estrategistas e decisores da ECT no período de 17 a 20 de junho de 2008. A pesquisa sobre a inter-relação dos subfatores da GCE obteve 167 respostas válidas dos estrategistas e decisores no período de 24 a 27 de julho de 2008. Os questionários aplicados continham 67 perguntas relacionadas aos subfatores da GCE, utilizando a escala likert de 5 pontos que indicava o grau de concordância do respondente em relação a cada questão (afirmativa) dos questionários. Foram realizadas análises estatísticas descritivas nos resultados da pesquisa.

\section{RESULTADOS DA PESQUISA}

Para avaliar o comportamento dos subfatores da GCE quando aplicados a uma organização, foram calculados os percentuais que representam o grau de concordância dos respondentes da pesquisa, somandose os que concordaram totalmente e os que concordaram em parte com as afirmativas. As principais conclusões extraídas da análise dos resultados em relação ao grau de concordância com as afirmativas relacionadas aos subfatores foram:

- percentual de estrategistas e decisores que usam a experiência: no compartilhamento de conhecimento $(92,5 \%)$, no processo de pensamento estratégico $(96,1 \%)$ e na hora da tomada de decisão $(99,2 \%)$;

- usam a intuição e o bom senso no compartilhamento do conhecimento $(98,0 \%)$ e na tomada de decisão $(90,6 \%)$;

- usam o discernimento e a razão no processo de planejamento e formulação das estratégias (94,5\%), e na transferência de conhecimento estratégico $(95,3 \%)$;

- concordam que os sistemas de informação são importantes para a formulação de estratégias (96,9\%), utilizam sistemas de informação para tomada de decisão $(89,0 \%)$, mas apenas $62,2 \%$ participam de alguma comunidade de prática;

- utilizam técnicas e métodos da administração para realizar as atividades de formulação e tomada de decisão estratégica (81, 1\%), Consideram o balanced scorecard (BSC) uma ferramenta interessante no processo de planejamento estratégico (83,5\%). A concordância sobre a utilização de Técnicas e Métodos no processo estratégico indica a integração desse subfator no processo;

- estrategistas e decisores indicaram que conhecer, divulgar e considerar os valores organizacionais faz parte do processo estratégico. $\mathrm{Na}$
261 
tomada de decisão, levam em consideração a missão, a visão e os valores da empresa $(88,6 \%)$;

- a liderança tem um papel importante na gestão do conhecimento estratégico. $\bigcirc$ papel do líder no compartilhamento do conhecimento é reconhecido pelos estrategistas e decisores. Como líder, devem compartilhar conhecimento $(99,2 \%)$; dão apoio às pessoas no processo de formulação estratégica $(90,9 \%)$.

- há uma concordância quanto à influência da autoridade do estrategista e decisor no processo de formulação estratégica (82,7\%). A estrutura de poder influencia também na gestão do conhecimento a partir do momento em que estrategista e decisores concordam que devido à posição profissional que ocupam, eles são responsáveis pela geração de conhecimento na empresa $(96,5 \%)$;

- o compartilhamento do conhecimento é um processo importante que faz parte da gestão do conhecimento, mas na prática também é um item que necessita de melhoria. Estrategistas e decisores dizem compartilhar informações $(93,3 \%)$, mas desconfiam da mesma atitude dos demais colaboradores, pois apenas $72,8 \%$ concordam que os demais compartilham informações com ele;

- estrategistas e decisores concordam que pessoas integradas compartilham mais o conhecimento $(98,4 \%)$;

- as pessoas sentem-se motivadas em participar do processo de pensamento estratégico $(96,1 \%)$ e estrategista e decisores concordam que o compartilhamento de informações e conhecimento é favorecido quando as pessoas estão motivadas $(97,2 \%) ; \mathrm{e}$

- conhecer o contexto organizacional e o ambiente em que atua é importante para que a empresa consiga estabelecer seu plano estratégico e tomar decisão. Estrategistas e decisores concordam que, na hora de tomar uma decisão, levam em consideração o contexto vivido pela organização $(96,5 \%)$ e, antes de formular estratégias e tomar decisões estratégicas, avaliam o ambiente da empresa $(91,3 \%)$.

Em relação ao segundo objetivo de avaliar a inter-relação dos subfatores da Gestão do Conhecimento Estratégico quando analisados sob o ponto de vista de uma organização pública, os principais resultados apresentados foram:

- estrategistas/decisores motivados influenciam no ambiente organizacional - 92,5\%;

- a experiência ajuda estrategistas/decisores no momento de liderança - 91,5\%;

- a postura e personalidade de estrategistas/decisores influenciam na integração das pessoas - 90,6\%;

- a experiência de estrategistas/decisores influencia na motivação das pessoas - 89,9\%;

- estrategistas/decisores integrados compartilham melhor as informações e os conhecimentos - 89,8\%;

- estrategistas/decisores integrados influenciam no ambiente organizacional - 89,8\%;

- estrategistas/decisores motivados ajudam na integração das pessoas - 89,6\%;

- recursos tecnológicos ajudam e facilitam no compartilhamento de informação e conhecimento no nível estratégico da empresa - 89,4\%;

- estrategistas/decisores motivados ajudam no compartilhamento de informações e conhecimentos - 89,4\%;

- o uso de recursos tecnológicos facilita o trabalho das lideranças estratégicas - 89,3\%;

- a personalidade e postura de estrategistas/decisores influenciam na sua forma de liderança $89,3 \%$;

- o ambiente organizacional é influenciado pelo exercício da liderança dos estrategistas/decisores $88,9 \%$;

- o ambiente organizacional é influenciado pela postura e personalidade de estrategistas/decisores - 88,9\%;

- a postura e personalidade dos estrategistas/decisores influenciam na motivação das pessoas - 88,6\%;

- o compartilhamento de informações entre estrategistas/decisores é facilitado quando se conhece a missão e os objetivos da empresa 88,0\%;

- o compartilhamento de informações e conhecimentos entre estrategistas/decisores influencia no ambiente organizacional - 87,8\%; 
- a postura e personalidade dos estrategistas/decisores da empresa influenciam na habilidade de divulgar os valores da organização - 87,5\%;

- há melhor integração entre estrategistas/decisores quando há disseminação da missão, dos objetivos e dos valores da empresa - 87,1\%;

- o uso de técnicas e métodos de gestão facilita o compartilhamento de informações e conhecimentos no nível estratégico - 86,9\%;

- a disseminação da missão, objetivos e valores da empresa pelos estrategistas/decisores influencia no ambiente organizacional - 86,9\% e

- o uso de técnicas e métodos ajuda na disseminação dos objetivos e valores da organização pelos estrategistas/decisores - 86,4\%.

Percebe-se que as relações entre os subfatores identificadas na pesquisa confirmam os discursos de estudiosos da Ciência da Informação e de outras Ciências. Nonaka e Takeuchi (1997), por exemplo, consideram que a estrutura de poder tem influência no processo de criação do conhecimento a partir do momento em que descrevem que gerentes estão posicionados na interseção dos fluxos vertical e horizontal de informação da empresa, e, por ter muito conhecimento, os qualificam como líderes de equipe responsáveis pela criação do conhecimento. Essa visão corrobora com o resultado da pesquisa que relaciona o subfator "estrutura de poder" com os subfatores "integração" e a "liderança". Outro resultado da pesquisa mostra que o subfator que tem o maior relacionamento com o subfator "Arquitetura da Informação" é o "Compartilhamento" e isso vai ao encontro do que descreve Figueiredo (2005), ao relatar que a tecnologia da informação estimula tanto as trocas quanto o compartilhamento de informações e conhecimento. Ele afirma que a Gestão do Conhecimento, sem o apoio da tecnologia da informação, pode ser praticamente impossível. $\bigcirc$ subfator "Compartilhamento", por sua vez, tem sua relação mais forte com o subfator "integração", confirmando as afirmações de Mclnerney (2006), ao descrever que podem ocorrer muitos problemas inerentes ao compartilhamento do conhecimento, se a cultura organizacional for mais competitiva do que colaborativa, se houver mudanças constantes, se houver empregados trabalhando em lugares distantes ou se não houver confiança entre as pessoas.
Em relação ao terceiro objetivo - estabelecer o detalhamento dos subfatores sistêmicos do modelo da Gestão do Conhecimento Estratégico, à luz da Ciência da Informação -, o estudo do referencial teórico mostrou que os subfatores da GCE são temas que compõem estudos da Ciência da Informação: Davenport e Prusak (1998) tratam da Experiência e Liderança; Brookes (1980) trata dos Processos Mentais; Choo (2006), da Capacidade de Julgamento; Terra (2001), da Arquitetura da Informação; Nonaka e Takeuchi (1997), Takeuchi e Nonaka (2008) tratam da Estrutura de Poder e do Compartilhamento; Alvarenga Neto (2008), das Técnicas e Métodos; Miranda (1993) trata da Proposição Clara de Valor; Sveiby (1997) aborda a Motivação; Marchiori (2002) trata da Integração e Moresi (2001), do Contexto, todos relacionando os subfatores no estudos da Ciência da Informação.

\section{CONCLUSÃO}

As principais conclusões sobre o estudo da GCE quando aplicados a uma organização foram:

- foi possível detalhar os subfatores sistêmicos do modelo da GCE à luz da Ciência da Informação, sob o aspecto do uso da informação e do estudo dos autores da GC e Cl que abordam esses subfatores;

- foi possível avaliar a inter-relação dos subfatores da CGE, quando analisados sob o ponto de vista de uma organização pública;

- os subfatores que apresentaram inter-relações mais fortes foram o contexto, a estrutura de poder, o compartilhamento, a motivação e a integração;

- o ambiente organizacional tende a ser influenciado pela postura dos estrategistas/decisores, pela liderança exercida por eles, pela ação de compartilhar informações e pelo fato de estarem motivados e integrados;

- a postura dos estrategistas/decisores tende a influenciar fortemente, também, na integração da pessoas, na sua forma de liderança e na disseminação dos valores organizacionais;

- o compartilhamento de informações tende a ser facilitado, quando os estrategistas/decisores estão integrados e motivados, quando há recursos 
tecnológicos disponíveis e quando os valores da organização estão disseminados;

- a experiência e a postura dos estrategistas/decisores tendem a estar relacionadas à capacidade de motivar pessoas; além disso, a motivação tende a ter relação com a integração e o compartilhamento de informações e

- o subfator que obteve um conjunto de inter-relações mais fraco foi "Processos Mentais", que está relacionado ao uso do bom senso e da intuição.

\section{REFERÊNCIAS}

ALMEIDA, M.B. Um modelo baseado em ontologias para representação da memória organizacional. 2006. 345f. Tese (doutorado em Ciência da Informação) - Escola da Ciência da Informação, Universidade Federal de Minas Gerais, 2006.

ALVARENGA NETO, R.C.D. Gestão do conhecimento em organizações: proposta de mapeamento conceitual integrativo. São Paulo: Saraiva, 2008

ANSOFF, H.I. A nova estratégia empresarial. São Paulo: Atlas, 1990.

ANSOFF, H.I. Implantando a administração estratégica. São Paulo: Atlas, 1993.

ARAÚJO, V.M.R.H. Sistemas de informação: nova abordagem teórico-conceitual. Ciência da informação, v.24, n. 1, 1995.

ARAÚJO JR. R.H. Uso da técnica SWOT em unidades arquivísticas: subsídios para o planejamento estratégico. In: CONGRESSO DE ARQUIVOLOGIA DO MERCOSUL, 6., 2005, Campos do Jordão. Anais... Campos do Jordão, [s.n], 2005.

BENNIS, W. Tornando-se um líder de líderes. In: GIBSON, R. (ed.). Repensando o futuro. São Paulo: Makron Books do Brasil, 1998.

BIANCHI, F. Proposta de aplicação de uma metodologia do planejamento estratégico, no processo de busca e uso da informação, nas organizações. Revista Cientifica do IMAPES, v.5, n.5, p. $49-58,2007$.

BOSSIDY, L. CHARAM, R. Execução: a disciplina para atingir resultados. Rio de Janeiro: Elsevier, 2005.

BROOKES, B.C. The foundation of information science: part I. Philosophical aspects. Journal of Information Science, v. 2, n. 3 4, p.125-133, 1980.

CALDAS, L.C.A. Arquitetura da informação e governo eletrônico: diálogo cidadãos-estado na world wide web: estudo de caso e avaliação ergonômica de usabilidade de interfaces humanocomputador, 2007. 354f. Tese (doutorado em Design) - Departamento de Arte e Design, Pontifícia Universidade Católica do Rio de Janeiro, Rio de Janeiro, 2007.

CASTRO, J.M. ABREU, P.G.F. Influência da inteligência competitiva em processos decisórios no ciclo de vida das organizações. Ciência da Informação, v.35, n.3, p. 15-29, 2006.
CHOO, C.W. A organização do conhecimento: como as organizações usam a informação para criar significado, construir conhecimento e tomar decisões. São Paulo: Editora Senac, 2006.

COVEY, S. Colocando os princípios em primeiro lugar. In GIBSON, R. Repensando o futuro. São Paulo: Makron Books, 1998.

DAVENPORT, T. H.; PRUSAK, L. Conhecimento empresarial: como as organizações gerenciam o seu capital intelectual. 4. ed. Rio de Janeiro: Campus, 1998.

FIGUEIREDO, S.P. Gestão do conhecimento: estratégias competitivas para a criação e mobilização do conhecimento na empresa: descubra como alavancar e multiplicar o capital intelectual e o conhecimento da organização. Rio de Janeiro: Qualitymark, 2005.

FLEURY, M.T.L.; OLIVEIRA, Jr., M.M. Gestão estratégica do conhecimento: integrando aprendizagem, conhecimento e competências. São Paulo: Atlas, 2001.

GHEMAWAT, P. A estratégia e o cenário dos negócios. Porto Alegre: Bookman, 2000.

GIL, A.C. Como elaborar projetos de pesquisa. São Paulo: Atlas, 2002.

GOLEMAN, D.; BOYATZIS, R.; McKEE, A. O poder da inteligência emocional: a experiência de liderar com sensibilidade e eficácia. Rio de Janeiro, Campus, 2002.

HAIR, J.F. Jr. et al. Análise multivariada de dados. Porto Alegre: Bookman, 2005

HAMMER, M. Além do fim da administração. In: GIBSON, R. Repensando o futuro. São Paulo: Makron Books, 1998.

HIAM, A. Liderança para gerentes e executivos. São Paulo: M. Books do Brasil Editora, 2004.

KAPLAN, R. S., NORTON, D. P. A estratégia em ação: balanced scorecard. Rio de Janeiro: Campus, 1997.

KAPLAN, R.S.; NORTON, D.P. Organização orientada para a estratégia: como as empresas que adotam o balanced scorecard prosperam no novo ambiente de negócios. Rio de Janeiro: Elsevier, 2000. 
KOTTER, J. Liderando mudança. Rio de Janeiro: Campus, 1999.

LAUDON, K.C.; LAUDON, J.P. Sistemas de informação com internet. 4. ed. Rio de Janeiro: LTC, 1999.

MARCHIORI, P.Z. A ciência e a gestão da informação: compatibilidade no espaço profissional. Ciência da Informação,v.31, n.2, p. 72-74, 2002.

MAROCO, J. Análise estatística com utilização do SPSS. Lisboa: Silabo, 2003.

McINERNEY, C.R. Compartilhamento e gestão do conhecimento: profissionais da informação em um ambiente de confiança mútua. In: TARAPANOFF, K.M.A (Org.) Inteligência, informação e conhecimento. Brasília: IBICT, UNESCO, 2006.

MINTZBERG, H. A criação artesanal da estratégia In.: MONTGOMERY, C.; PORTER, M. Estratégia: a busca da vantagem competitiva. Rio de Janeiro: Campus, 1998.

MINTZBERG, H. Ascensão e queda do planejamento estratégico. Porto Alegre: Bookman, 2004.

MIRANDA, A. Os conceitos de organização baseada na informação e no conhecimento e o desenvolvimento de serviços bibliotecários. Ciência da Informação, v. 22, n. 3, p. 227-232, 1993.

MIRANDA, R.C.R. Gestão do conhecimento estratégico: proposta de um modelo integrado. 2004. 268p. Tese (doutorado em Ciência da Informação) - Departamento da Ciência da Informação e Documentação, Universidade de Brasília, 2004.

MIRANDA, R.C.R.; GASPAR, J.F.A. Técnicas de elicitação do conhecimento tácito: uma avaliação comparada. In: TARAPANOFF, K.M.A (Org.) Inteligência, informação e conhecimento. Brasília: IBICT, UNESCO, 2006.

MORESI, E.A.D. Monitoramento ambiental. In. TARAPANOFF, K. (Org.) Inteligência organizacional e competitiva. Brasília: Editora Universidade de Brasília, 2001.

MOURA, M.A. Ciência da informação e semiótica: conexão de saberes. Enc. Bibli: R. Eletr. Bibliotecon. Ci. Inf., n.2 esp., 2006.

NONAKA, I.; TAKEUCHI, N. Criação de conhecimento na empresa. Rio de Janeiro. Elsevier, 1997.

O'BRIEN, J.A. Sistemas de informação e as decisões gerenciais na era da internet. São Paulo: Saraiva, 2001.

OLIVEIRA, D.P.R. Estratégia empresarial e vantagem competitiva: como estabelecer, implementar e avaliar. São Paulo: Atlas, 2007.

PEREIRA, M. J. L. de B.; FONSECA, J. G. M. Faces da decisão. São Paulo: Makron Books, 1997.

PORTER, M. Estratégia competitiva: técnicas para análise de indústrias e da concorrência. Rio de Janeiro: Campus, 1986.
PORTER, M. Criando as vantagens de amanhã. In: GIBSON, R. Repensando o futuro. São Paulo: Makron Books, 1998.

PRAHALAD, C.K., HAMEL G. A competência essencial da corporação. In: MONTGOMERY, C. A., PORTER, M. E. Estratégia: a busca da vantagem competitiva. Rio de Janeiro: Campus, 1998.

RENAULT, L.V.; MARTINS, R. O retrato da ciência da informação: uma análise de seus fundamentos sociais. Enc. Bibli: R. Eletr. Bibliotecon. Ci. Inf., n.23, 2007.

RIBEIRO, R.M.R. Motivação dos recursos humanos em bibliotecas universitárias. Revista Digital de Biblioteconomia e Ciência da Informação, v. 2, n. 1, p. 71-79, 2004.

ROBBINS, S.P. Fundamentos do comportamento organizacional. São Paulo: Prentice Hall, 2004.

ROSENFELD, L.; MORVILLE, P. Information architecture for the World Wide Web. 2. ed. Sebastopol: O'Reilly, 2002.

SANTIAGO JR.; J.R.S. Gestão do conhecimento: a chave para o sucesso empresarial. São Paulo: Novatec Editora, 2004.

SANTOS, P.M.L. O ponto de inflexão Otlet: uma visão sobre as origens da documentação e o processo de construção do princípio monográfico. 2006. 138p. Dissertação (mestrado em Ciência da Informação) - Escola de Comunicações e Artes - Universidade de São Paulo, 2006.

SARACEVIC, T. Ciência da Informação: origem, evolução e relações. Perspectivas em Ciência da Informação, v. 1, n. 1, p.|4 1-62, 1996.

SENGE, P.M. Pelo buraco da agulha. In: GIBSON, R. Repensando o futuro. São Paulo: Makron Books, 1998.

SIQUEIRA, M.M. Medidas do comportamento organizacional. Estudos de Psicologia, v.7, n. esp., p. 11 -18, 2002.

STACEY, R.D. Strategic management and organizational dynamics: the challenge of complexity. London, Pitman, 2000.

SVEIBY, K.E. The new organizational wealth: managing and measuring knowledge-based assets. San Francisco: BerrettKoehler Publisher, 1997.

TAKEUCHI, H.; NONAKA, I. Gestão do conhecimento. Porto Alegre: Bookman, 2008.

TARAPANOFF, K.M.A. Informação, conhecimento e inteligência em corporações: relações e complementaridade. In: TARAPANOFF, K.M.A (Org.) Inteligência, informação e conhecimento. Brasília: IBICT, UNESCO, 2006.

TERRA, J.C.C. Gestão do conhecimento: o grande desafio empresarial: uma abordagem baseada no aprendizado e na criatividade. São Paulo: Negócio Editora, 2001.

TEIXEIRA FILHO, J. Gerenciando conhecimento: como a empresa pode usar a memória organizacional e a inteligência com- 
petitiva no desenvolvimento de negócios. Rio de Janeiro: SENAC, 2000.

TOMAÉL, M.I. Redes de conhecimento. DataGramaZero: revista de Ciência da Informação, v.9, n.2, 2008.

TROUILLET, S.A. Criatividade, intuição e planejamento estratégico: a aplicação do conhecimento. [S.I.]: UFSC; Enegep: 1998.

VALENTIM, M.L.P.; GELINSKI, J.V.V. Gestão do conhecimento como parte do processo de inteligência competiti- va organizacional. Inf. \& Soc.: Est., v. 15, n. 2, p. 41-59, 2005.

VANTI, N. Ambiente de qualidade em uma biblioteca universitária: aplicação do $5 \mathrm{~S}$ e de um estilo participativo de administração. Ciência da Informação, v. 28, n. 3, p. 333-339, 1999.

WRIGHT, P. L.; MARK, J.K.; PARNELL, J. Administração estratégica: conceitos. São Paulo: Atlas, 2000. 